12,13

\title{
Изменение химического состояния и концентрации железа в углеродных нанотрубках, полученных методом CVD и подвергнутых импульсному ионному облучению
}

\author{
(C) П.М. Корусенко ${ }^{1}$, С.Н. Несов ${ }^{1}$, В.В. Болотов ${ }^{1}$, С.Н. Поворознюк ${ }^{1,2}$, \\ А.И. Пушкарев ${ }^{3}$, Е.В. Князев ${ }^{1}$ \\ ${ }^{1}$ Омский научный центр СО РАН, \\ Омск, Россия \\ ${ }^{2}$ Омский государственный технический университет, \\ Омск, Россия \\ ${ }^{3}$ Национальный исследовательский Томский политехнический университет, \\ Томск, Россия \\ E-mail: korusenko@obisp.oscsbras.ru
}

(Поступила в Редакцию 29 марта 2017 г.)

С использованием методов просвечивающей электронной микроскопии, рентгенофотоэлектронной спектроскопии и энергодисперсионного анализа получены данные о распределении железа в азотсодержащих многостенных углеродных нанотрубках (N-MУНТ), изменении его химического состояния и концентрации при различных режимах облучения импульсным ионным пучком. Показано, что облучение N-MУНT с плотностью энергии $0.5 \mathrm{~J} / \mathrm{cm}^{2}$ способствует формированию на их боковых поверхностях структур размером 2-10 nm, состоящих из металлического железа, инкапсулированного в углеродную оболочку. Повышение плотности энергии до $1-1.5 \mathrm{~J} / \mathrm{cm}^{2}$ приводит к существенному удалению кластеров железа из вершин углеродных нанотрубок и снижению количества железа в объеме слоя N-МУНТ.

Работа выполнена при частичной поддержке РФФИ (гранты № 15-42-04308-р_сибирь_а, 16-08-00763 a).

DOI: $10.21883 /$ FTT.2017.10.44974.102

\section{1. Введение}

В настоящее время углеродные нанотрубки (УНТ) являются предметом интенсивных исследований в связи с их уникальной электронной структурой, электрическими и механическими свойствами [1]. Известно [2,3], что при синтезе УНТ методом CVD (chemical vapor deposition) в качестве катализатора роста часто применяются переходные металлы (Fe, Co, Ni). При этом частицы катализатора, встроенные в структуру УНТ, взаимодействуют со стенками нанотрубок и могут значительно влиять на электронную структуру и свойства нанотрубок. В частности, в [4] показано, что транспорт электронов из частиц катализатора в УНТ повышает адсорбцию кислородсодержащих групп на их поверхности. Встроенные в структуру УНТ частицы катализатора могут изменять активность углеродных слоев нанотрубок в различных окислительных реакциях, что может быть перспективно для применения в гетерогенном катализе [5]. Кроме того, углеродная оболочка защищает железосодержащие наночастицы от окисления, предотвращает спонтанную агломерацию и изменение их свойств [5-7]. С другой стороны, во многих случаях наличие частиц металлического катализатора в УНТ является нежелательным $[8,9]$. Имеется большое число работ, направленных на удаление металлических частиц с использованием методов мокрой химии (например, кислотной обработки в $\left.\mathrm{H}_{2} \mathrm{SO}_{4} / \mathrm{HCl}\right)$ или термической обработки в инертных средах [10-12]. Высокотемпературный отжиг в инертных средах является более предпочтительным видом обработки, так как позволяет существенно снизить концентрацию металлического катализатора в УНТ до значений $<0.01$ wt.\%, не нарушая структуру внешних стенок УНТ [13-15].

Широкие возможности для модифицирования свойств многостенных УНТ (МУНТ) возникают при использовании импульсного ионного пучка высокой удельной мощности $[16,17]$. За счет введения большого количества энергии $\left(>10^{7} \mathrm{~W} / \mathrm{cm}^{2}\right)$ за время действия импульса ( 120 ns) возникают высокие градиенты температуры и давления, способные изменять морфологию и воздействовать на электронную структуру материала, а также формировать новые структурно-фазовые состояния. На настоящий момент в литературе отсутствуют данные по влиянию импульсного ионного облучения на концентрацию и химическое состояние железа в МУНТ.

Целью настоящей работы является исследование изменения электронной и атомной структуры наночастиц железа, инкапсулированных в азотсодержащие МУНТ (N-MУНТ), а также концентрации железа после воздействия импульсного ионного пучка наносекундной длительности при различной плотности энергии воздействия. В работе использовались методы просвечивающей микроскопии (ПЭМ), рентгенофотоэлектронной спектроскопии (РФЭС) и энергодисперсионный анализ (ЭДА). 


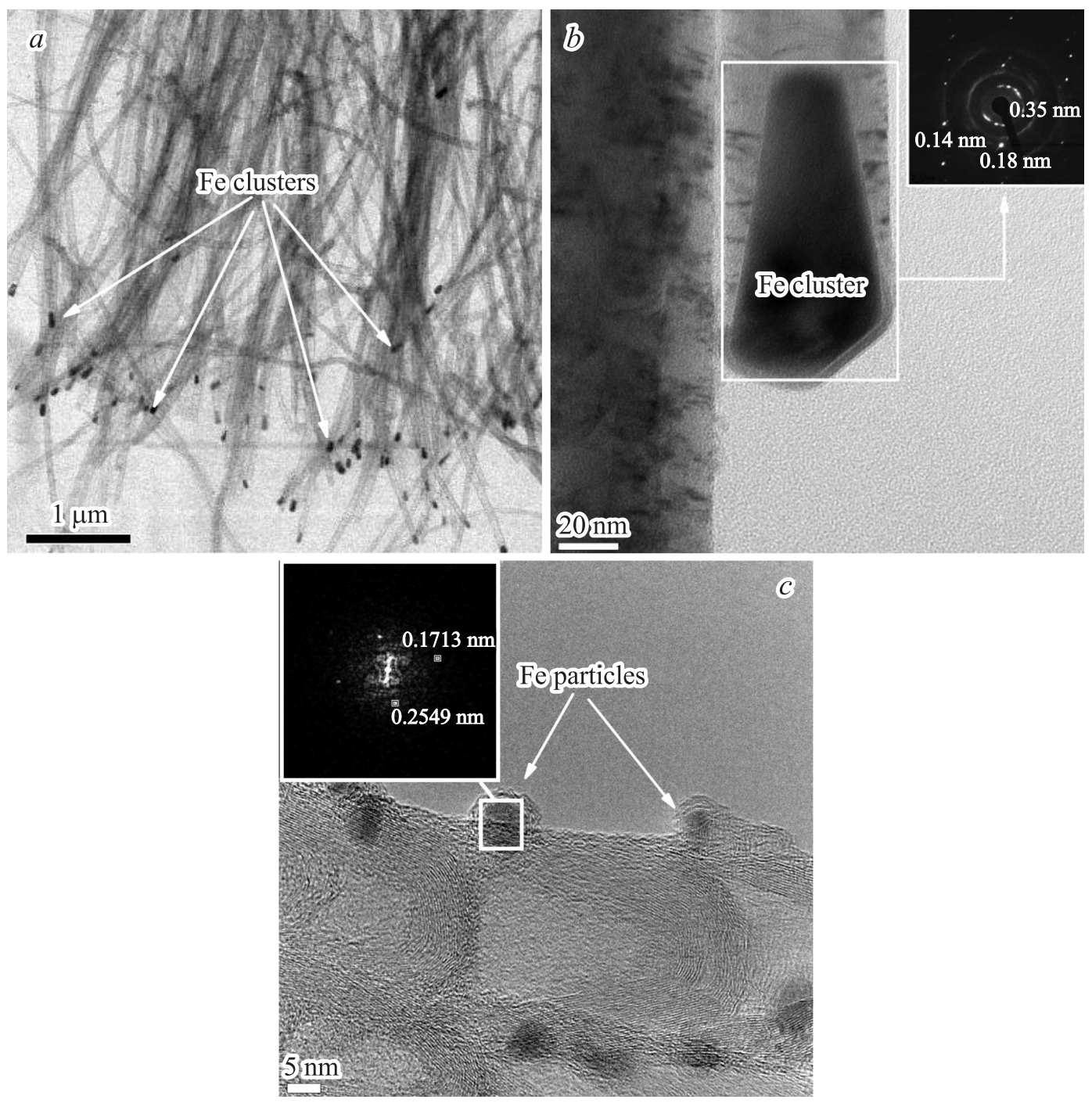

Рис. 1. ПЭМ-изображения исходных N-MУНТ с различным расположением железосодержащего катализатора. $a-$ общий вид (в режиме сканирования), $b$ - кластеры катализатора в вершинах нанотрубок, $c$ - частицы железа на боковых поверхностях нанотрубок.

\section{2. Эксперимент}

Слои N-MУНТ формировались методом CVD при пиролизе смеси ацетилонитрила и ферроцена $(100: 1)$ на подложках из кремниевых пластин с оксидным слоем толщиной $\sim 100 \mathrm{~nm}$. Пиролиз осуществлялся при температуре $800^{\circ} \mathrm{C}$ в потоке аргона $(150 \mathrm{ml} / \mathrm{min})$. Синтез исходных слоев углеродных нанотрубок продолжался в течение $15 \mathrm{~min}$. Толщина слоя N-MУНТ составляла $\sim 11 \mu \mathrm{m}$. Средний диаметр исходных углеродных нанотрубок составляет $\sim 30-50 \mathrm{~nm}$, а суммарная толщина стенок $10 \mathrm{~nm}$.

Облучение слоев ориентированных N-МУНТ проводилось импульсным ионным пучком на ускорителе ТЕМП4M [18] (в Томском политехническом университете) со следующими параметрами: состав пучка $\mathrm{H}^{+}-15 \%$, $\mathrm{C}^{+}-85 \%$, энергия $250 \mathrm{keV}$, длительности импульса $120 \mathrm{~ns}$, плотность энергии $0.5,1$ и $1.5 \mathrm{~J} / \mathrm{cm}^{2}$, количество импульсов 1. Расчетное значение проективного пробега протонов и ионов углерода в слое N-МУНТ для данных параметров облучения составляет $\sim 23$ и $\sim 5 \mu \mathrm{m}$ соответственно [17].

Морфология и структурное состояние исходных и облученных слоев N-МУНТ изучались с использованием ПЭМ на микроскопе JEOL JEM 2100. Исследование химического состояния и концентрации железа в N-МУНТ осуществлялось с применением поверхностночувствительного метода РФЭС, реализованного на аналитическом комплексе Kratos Axis Ultra DLD. Измерения проводились в сверхвысоком вакууме при давлении остаточных газов в измерительной камере не выше $\sim 10^{-9}$ Torr. Для возбуждения рентгеновских спектров применялось монохроматизированное $\mathrm{A} 1 K_{\alpha}$-излучение $(h v=1487 \mathrm{eV})$. Спектры фотоэмиссии О $1 s-$, Fe $2 p-$ и $\mathrm{Fe} 3 p$-электронов записывались с использованием полусферического анализатора в режиме с фиксированной 

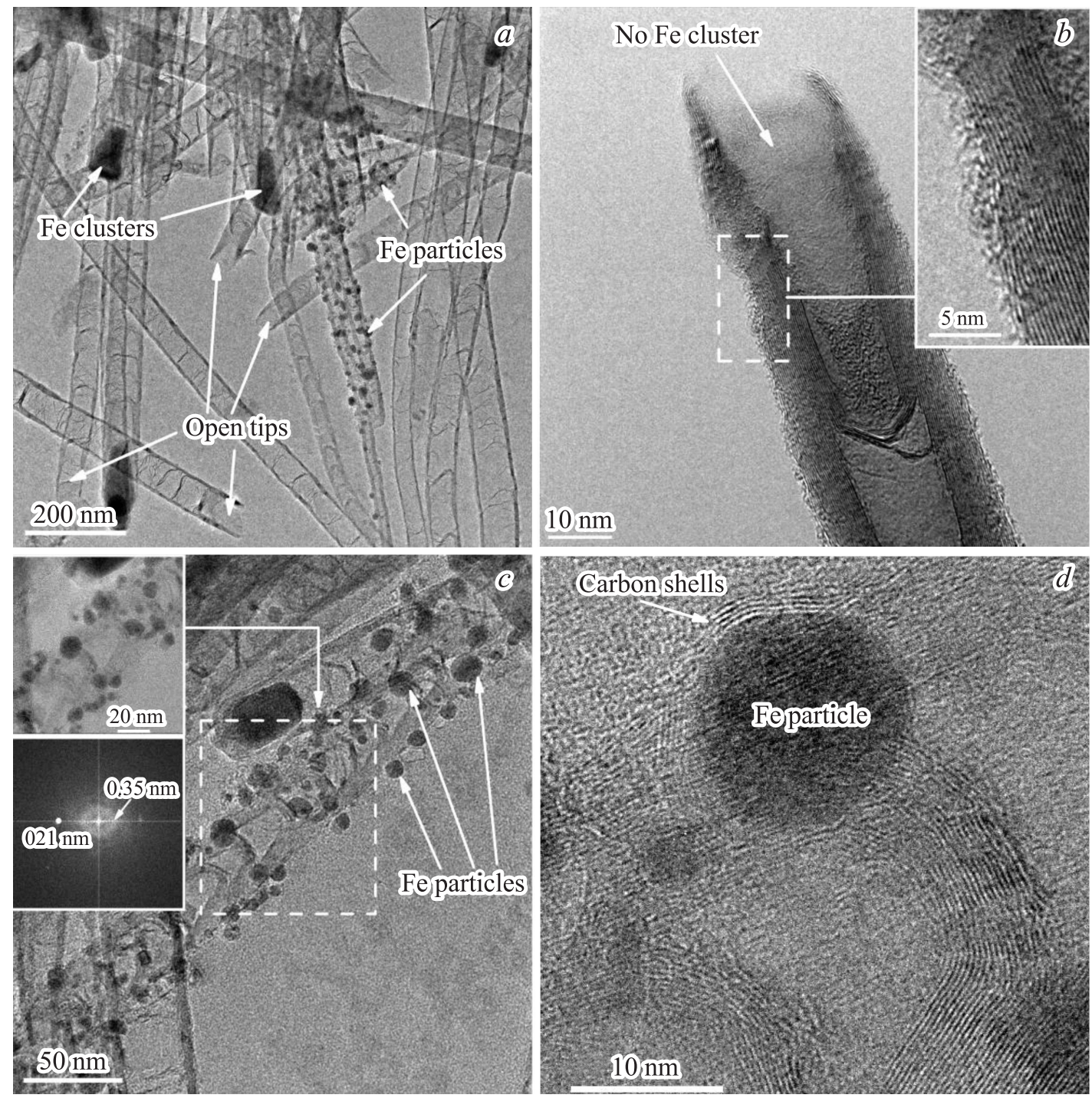

Рис. 2. ПЭМ-изображения N-MУНТ после облучения импульсным ионным пучком с $0.5 \mathrm{~J} / \mathrm{cm}^{2}$. $a$ - нанотрубки с открытыми концами и с частицами катализатора на боковых поверхностях, $b$ - индивидуальная N-МУНТ (на вставке выделенная область с высоким разрешением), $c$ - N-МУНТ с частицами катализатора на боковых поверхностях (на вставке электронная микродифракция с выделенного участка), $d$ - инкапсулированная частица железа в графитовой оболочке на боковой поверхности нанотрубки.

энергией пропускания $40 \mathrm{eV}$ (для $\mathrm{Fe} 2 p, \mathrm{O} 1 s$ ) и $160 \mathrm{eV}$ (для $\mathrm{Fe} 3 p$ ). Аппроксимация линии $\mathrm{Fe} 2 p_{1 / 2}$ была проведена с использованием функции Doniach-Sunjic с коэффициентом асимметрии, равным 0.07. Аппроксимация линии $\mathrm{O} 1 s$ была проведена с использованием комбинации функций Лоренца и Гаусса. Согласно расчетам авторов [19], глубина выхода фотоэлектронов с уровней $\mathrm{Fe} 2 p$ и $\mathrm{Fe} 3 p$ при возбуждении с $h v=1487 \mathrm{eV}$ составляет $\sim 2$ и $\sim 6 \mathrm{~nm}$ соответственно.

Количественный элементный состав слоев N-MУНТ определялся методом ЭДА на сканирующем электронном микроскопе JEOL JSM 6610 LV в центре коллективного пользования ОНЦ СО РАН. Данный метод позволил получить информацию о составе слоя N-МУНТ по всей его толщине.

\section{3. Результаты}

3.1. Данные ПЭМ. На рис. 1 приведены ПЭМизображения исходных N-MУНТ и данные электронной микродифракции.

Как видно, в исходных N-МУНТ основное количество железа сосредоточено в виде кластеров в вершинах нанотрубок (рис. $1, a$ ), где железо присутствует, в различных состояниях. Об этом, в частности, свидетельствуют данные микродифракции (рис. $1, b$, вставка). На электронной дифрактограмме наблюдаются яркие рефлексы $0.14,0.18$ и $0.35 \mathrm{~nm}$, соответствующие межплоскостным расстояниям для металлического $\gamma$ - $\mathrm{Fe}(200), \mathrm{Fe}_{3} \mathrm{C}(122)$ и углерода в стенках N-MУНT(002) соответственно. Это согласуется с результатами работы [20]. Помимо 

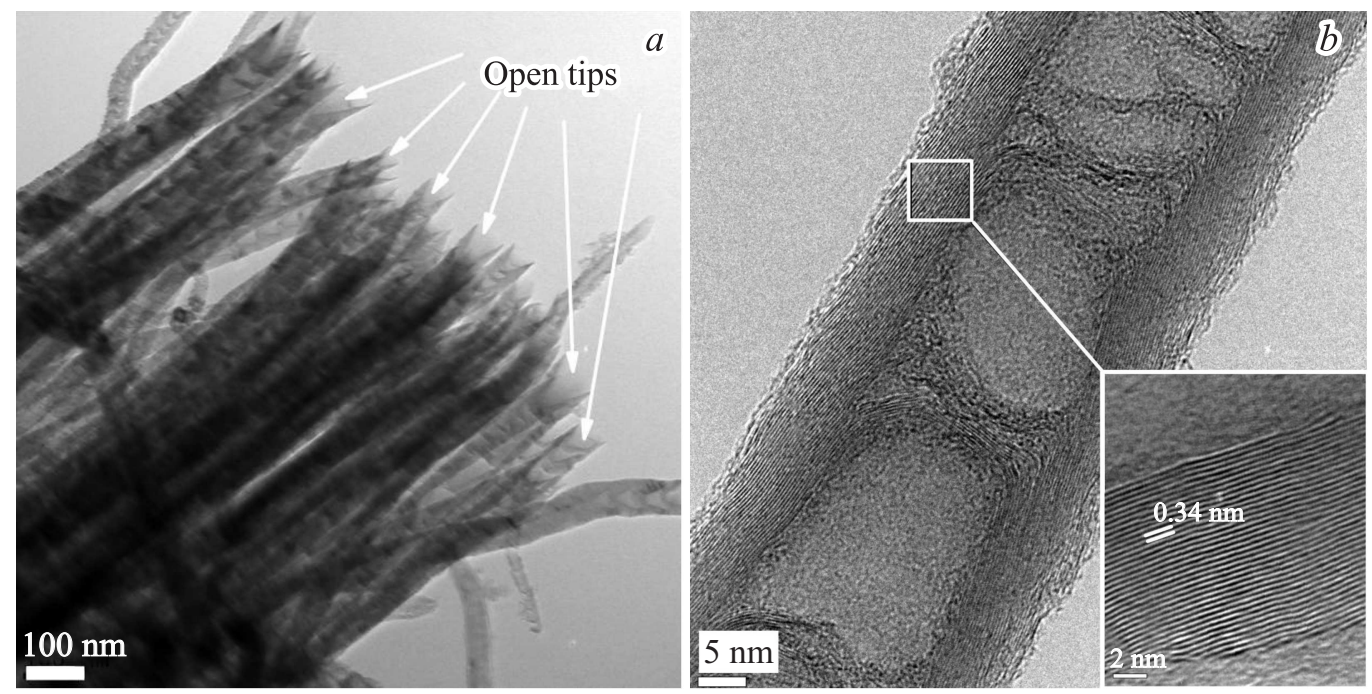

Рис. 3. ПЭМ-изображения N-МУНТ после облучения импульсным ионным пучком с $1.5 \mathrm{~J} / \mathrm{cm}^{2}$. $a-$ множество нанотрубок с открытыми концами, $b$ - индивидуальная углеродная нанотрубка (на вставке приведена выделенная область N-MУНТ с высоким разрешением).

этого встречаются частицы катализатора на боковых поверхностях N-MУНТ (рис. 1,c). Анализ электронной дифрактограммы для данного случая расположения частиц железосодержащего катализатора показал наличие межплоскостных расстояний $\sim 0.17$ и $0.25 \mathrm{~nm}$, которые отвечают плоскостям (116) и (101) для $\alpha-\mathrm{Fe}_{2} \mathrm{O}_{3}$ (рис. 1,c, вставка). Это согласуется с нашим предыдущим исследованием, где показано, что окисленное железо в N-МУНТ присутствует в $\alpha-\mathrm{Fe}_{2} \mathrm{O}_{3}$ [21].

Анализ ПЭМ-изображений облученных N-MУНТ при плотности энергии импульсного ионного пучка $0.5 \mathrm{~J} / \mathrm{cm}^{2}$ показал наличие определенной части углеродных нанотрубок с открытыми концами, в которых отсутствуют частицы катализатора (рис. 2,a). Вместе с тем наблюдается значительное количество N-МУНТ с поврежденными (дефектными) внешними стенками (рис. 2, $b$ ). При этом на боковых поверхностях углеродных нанотрубок наблюдаются структуры, состоящие из кластеров железа (от 2 до $10 \mathrm{~nm}$ ), покрытых оболочкой из нескольких слоев графитизированного углерода (рис. 2, $c, d$ ). Электронная микродифракция показала, что данные частицы состоят преимущественно из металлического железа $(d=2.1 \mathrm{~nm})$. Однако также нельзя исключать наличия некоторого количества железа в соединении $\mathrm{Fe}_{3} \mathrm{C}$.
Повышение плотности энергии облучения до $1-1.5 \mathrm{~J} / \mathrm{cm}^{2}$ способствует интенсификации процесса удаления железа из вершин N-MУНТ. Об этом свидетельствуют данные статистической обработки ПЭМ-изображений отдельных нанотрубок с открытыми концами. Наибольшее количество открытых нанотрубок, в которых отсутствуют частицы катализатора, зафиксировано для N-MУНТ, облученных при $1.5 \mathrm{~J} / \mathrm{cm}^{2}$ (рис. $3, a$ ). Также для данного режима облучения наблюдаются уменьшение количества частиц катализатора, закрепленных на боковых поверхностях N-MУНТ, и повышение степени упорядоченности кристаллической структуры стенок углеродных нанотрубок (рис. $3, b$ ).

3.2. Анализ слоев N-MУНТ методом ЭДА. ЭДА-анализ, проведенный для исходных и облученных с различной плотностью энергии воздействия N-МУНТ, показал присутствие углерода, кислорода, железа и кремния в спектрах всех образцов. Сигнал от кремния, регистрируемый в ЭДА-спектрах исследуемых образцов, связан с глубиной анализа данным методом, превышающей толщину слоя N-МУНТ $(\sim 11 \mu \mathrm{m})$. Как видно из данных количественного ЭДА-анализа (табл. 1), облучение импульсным ионным пучком приводит к снижению концентрации железа в слое N-MУНТ при увеличении

Таблица 1. Концентрация элементов по данным ЭДА

\begin{tabular}{c|c|r|r|r}
\hline \multirow{2}{*}{$\begin{array}{c}\text { Плотность энергии } \\
\text { облучения, } \mathrm{J} / \mathrm{cm}^{2}\end{array}$} & \multicolumn{4}{|c}{ Концентрация, at.\% } \\
\cline { 2 - 5 } & $\mathrm{C}$ & $\mathrm{Si}$ & $\mathrm{O}$ & $\mathrm{Fe}$ \\
\hline 0 (исходные N-МУНТ) & $97.24 \pm 0.10$ & $0.24 \pm 0.05$ & $1.77 \pm 0.02$ & $0.75 \pm 0.03$ \\
0.5 & $96.49 \pm 0.20$ & $0.92 \pm 0.19$ & $1.76 \pm 0.11$ & $0.83 \pm 0.04$ \\
1 & $96.45 \pm 0.24$ & $2.54 \pm 0.28$ & $0.9 \pm 0.09$ & $0.11 \pm 0.02$ \\
1.5 & $93.25 \pm 0.11$ & $5.88 \pm 0.35$ & $0.82 \pm 0.07$ & $0.05 \pm 0.02$
\end{tabular}



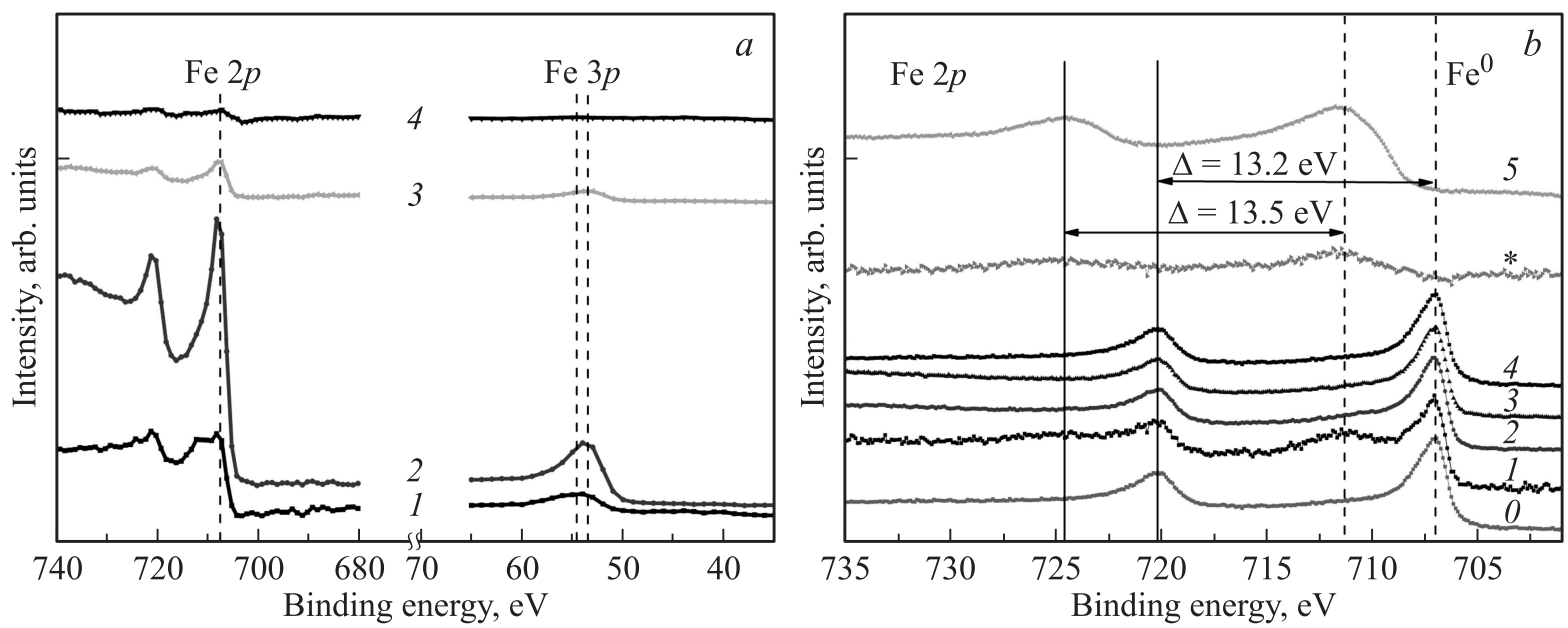

Рис. 4. a) РФЭ-спектры Fe $2 p$ и Fe $3 p$, измеренные при энергии пропускания анализатора 160 eV. $b$ ) Нормированные РФЭ-спектры $\mathrm{Fe} 2 p$, измеренные при энергии пропускания анализатора $40 \mathrm{eV}$. Цифрами обозначены кривые, отвечающие спектрам эталонного образца Fe $(0)$, исходных N-MУНТ (1), N-МУНТ, облученных при плотности энергии 0.5 (2), 1 (3), $1.5 \mathrm{~J} / \mathrm{cm}^{2}$ (4), и эталонного образца $\mathrm{Fe}_{2} \mathrm{O}_{3}(5)$. Звездочкой обозначен разностный спектр, полученный вычитанием кривой 1 из кривой 0 .

плотности энергии воздействия. Минимальная концентрация железа наблюдается для N-МУНТ, облученных импульсным ионным пучком с плотностью энергии $1.5 \mathrm{~J} / \mathrm{cm}^{2}$. Основываясь на данных ЭДА, можно сделать вывод, что облучение N-МУНТ с плотностью энергии $1-1.5 \mathrm{~J} / \mathrm{cm}^{2}$ приводит к снижению концентрации железа в объеме слоя нанотрубок.

3.3. Исследование химического состава и концентрации железа в слоях N-MУНТ методом РФЭС. На рис. 4 приведены рентгеновские фотоэлектронные (РФЭ) спектры остовных уровней $\mathrm{Fe} 2 p, \mathrm{Fe} 3 p$ железа для исходных и облученных импульсным ионным пучком N-MУНТ при различной плотности энергии воздействия. В спектре Fe $2 p$ исходных N-MУНТ железо присутствует в двух химических состояниях: в металлическом (с максимумом вблизи энергии связи $707.1 \mathrm{eV}$ ) и окисленном (с максимумом при $711.1 \mathrm{eV}$ ) (рис. 4, $a$ и $b$, кривые 1). Об этом также свидетельствует энергетическое расщепление линий $\mathrm{Fe}$ $2 p_{3 / 2}$ и $\mathrm{Fe} 2 p_{1 / 2}$ - параметр $\Delta$, позволяющий иденти- фицировать химическое состояние железа [22]. Так, для металлического железа значение данного параметра составляет $13.2 \mathrm{eV}$, а для окисленного состояния железа $13.5 \mathrm{eV}$ (рис. 4, $b$ ). При этом разностный спектр (отмечен звездочкой), полученный вычитанием кривой 1 (спектр образца исходных N-MУНТ) из спектра Fe (спектр образца металлического железа), практически идентичен спектру $\mathrm{Fe}_{2} \mathrm{O}_{3}$ (рис. 4,b).

Оценка средней стехиометрии оксида железа в исходных N-MУНТ была проведена с использованием данных количественного анализа, проведенного по обзорным РФЭ-спектрам (спектры не приведены), а также результатов разложения РФЭ-линии кислорода О $1 s$ (рис. 5, a, табл. 2) и железа Fe $2 p_{1 / 2}$ (рис. 5, $b$, табл. 2). Анализ РФЭ-линии кислорода О $1 s$ исходных N-MУНТ показал наличие трех химически неэквивалентных состояний кислорода. Компоненты при 533.2 и $532.1 \mathrm{eV}$ отвечают кислороду в составе связей $\mathrm{O}-\mathrm{C}$ и $\mathrm{O}=\mathrm{C}$ соответственно [12,23]. Компонента при $530.1 \mathrm{eV}$ отвечает кислороду, химически связанному с металлом

Таблица 2. Концентрация железа и кислорода по данным РФЭС-анализа в образцах N-МУНТ, облученных при различной плотности энергии импульсного ионного пучка

\begin{tabular}{|c|c|c|c|c|c|c|c|c|c|c|}
\hline \multirow{3}{*}{$\begin{array}{c}\text { Плотность } \\
\text { энергии } \\
\text { облучения, } \mathrm{J} / \mathrm{cm}^{2}\end{array}$} & \multicolumn{10}{|c|}{ Концентрация элементов, at.\% } \\
\hline & \multirow[t]{2}{*}{$\mathrm{C}$} & \multirow[t]{2}{*}{$\mathrm{N}$} & \multicolumn{4}{|c|}{$\mathrm{O}$} & \multicolumn{3}{|c|}{$\mathrm{Fe}$} & \multirow{2}{*}{$\mathrm{O}_{\mathrm{Fe}-\mathrm{O}} / \mathrm{Fe}_{\mathrm{ox}}$} \\
\hline & & & $\mathrm{O}_{\text {tot }}$ & $\mathrm{O}_{\mathrm{C}-\mathrm{O}}$ & $\mathrm{O}_{\mathrm{C}=\mathrm{O}}$ & $\mathrm{O}_{\mathrm{Fe}-\mathrm{O}}$ & $\mathrm{Fe}_{\text {tot }}$ & $\mathrm{Fe}_{\text {met }}$ & $\mathrm{Fe}_{\mathrm{ox}}$ & \\
\hline 0 (исходные N-MУНТ) & 92.40 & 3.20 & 3.80 & 0.92 & 2.47 & 0.41 & 0.60 & 0.31 & 0.29 & 1.42 \\
\hline 0.5 & 86.40 & 2.00 & 9.10 & 3.29 & 5.56 & 0.25 & 2.50 & 2.25 & 0.25 & 1.00 \\
\hline 1 & 96.30 & 1.20 & 2.30 & 1.10 & 1.20 & - & 0.20 & 0.20 & - & - \\
\hline 1.5 & 97.40 & 0.80 & 1.70 & 0.88 & 0.82 & - & 0.10 & 0.10 & - & - \\
\hline
\end{tabular}

При мечание. $\mathrm{O}_{\text {tot }}$ - общая концентрация кислорода, $\mathrm{O}_{\mathrm{C}-\mathrm{O}}-$ количество кислорода в связях $\mathrm{C}-\mathrm{O}$, О $\mathrm{C}=\mathrm{O}-$ количество кислорода в связях $\mathrm{C}=\mathrm{O}, \mathrm{O}_{\mathrm{Fe}} \mathrm{O}-$ количество кислорода в связях $\mathrm{Fe}-\mathrm{O}, \mathrm{Fe}_{\mathrm{tot}}-$ общая концентрация железа, $\mathrm{Fe}_{\mathrm{met}}-$ количество железа в металлическом состоянии, $\mathrm{Fe}_{\mathrm{ox}}$ - количество железа в оксиде. 

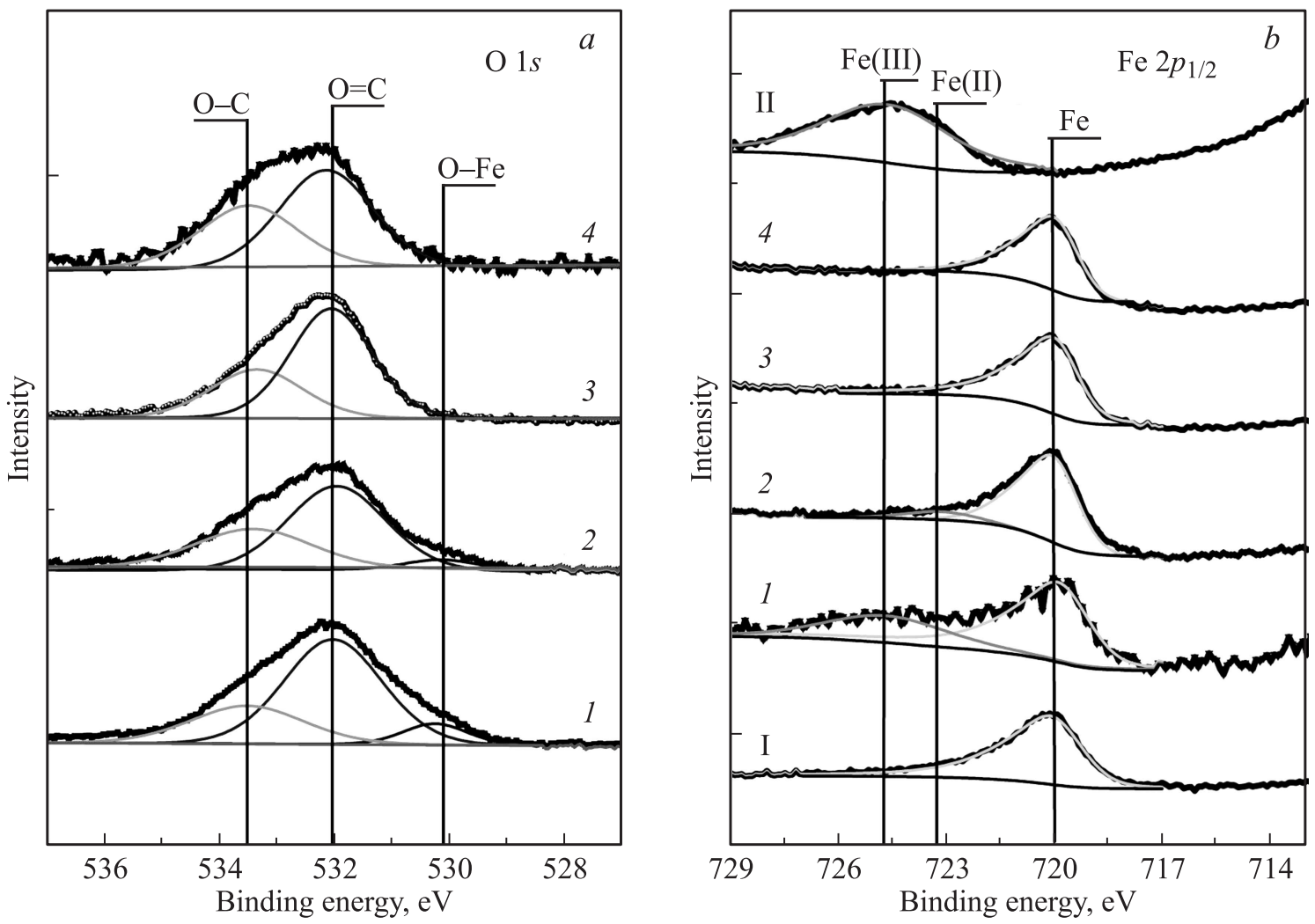

Рис. 5. Нормированные РФЭ-спектры O $1 s(a)$ и Fe $2 p_{1 / 2}(b)$ для исходных N-MУНТ (1) и облученных при плотности энергии импульсного ионного пучка $0.5(2), 1(3)$ и $1.5 \mathrm{~J} / \mathrm{cm}^{2}(4)$. Кривые I и II - спектры $\mathrm{Fe} 2 p_{1 / 2}$ эталонных образцов $\mathrm{Fe}_{\text {и }} \mathrm{Fe}_{2} \mathrm{O}_{3}$ соответственно.

$(\mathrm{O}-\mathrm{Fe})[12,23,24]$. Интегральная площадь компоненты спектра О $1 s$, соответствующей связи кислорода с железом $(\mathrm{O}-\mathrm{Fe})$, составляет $\sim 11 \%$, что дает в пересчете 0.41 at.\%. Детальный анализ химического состояния железа был проведен по линии $\mathrm{Fe} 2 p_{1 / 2}$, для которой процедура вычитания фоновой составляющей и аппроксимация линии являются более корректными, чем для $\mathrm{Fe} 2 p_{3 / 2}$. Разложение линии $\mathrm{Fe} 2 p_{1 / 2}$ исходных $\mathrm{N}-\mathrm{MУНТ} \mathrm{показало,} \mathrm{что} \mathrm{интегральная} \mathrm{площадь} \mathrm{(доля)}$ окисленного компонента железа составляет $\sim 50 \%$, а его количество - 0.29 at.\% (табл. 2). Таким образом, средняя стехиометрия соединений железа с кислородом в образце исходных N-МУНТ составляет 1.42, что достаточно близко к значению стехиометрии соединения $\mathrm{Fe}_{2} \mathrm{O}_{3}$. Следовательно, основываясь на данных ПЭМ и РФЭС, можно утверждать, что в исходных N-MУНТ железо присутствует преимущественно в состояниях $\mathrm{Fe}^{0}$ и $\mathrm{Fe}^{3+}$ (рис. 1, 5, табл. 2).

Облучение N-MУНТ при плотности энергии $0.5 \mathrm{~J} / \mathrm{cm}^{2}$ приводит к увеличению интенсивности компоненты железа в металлическом состоянии, а также к повышению процентного содержания железа (до 4 раз) в анализируемом слое образца ( $d$ до $6 \mathrm{~nm}$ ) в сравнении с исходными N-МУНТ (табл. 2, рис. 4,a). В то же время доля окисленной компоненты линии $\mathrm{Fe} 2 p$ существенно снижается (рис. 5, $b$, кривая 2). Вследствие этого наблюдается уменьшение значения средней стехиометрии соединений железа с кислородом до единицы (табл. 2). Кроме того, обнаружен сдвиг максимума линии $\mathrm{Fe} 3 p$ на $1 \mathrm{eV}$ в сторону низких энергий связи (рис. 4, $a$, кривая 2), а значение параметра $\Delta$ составляет $13.2 \mathrm{eV}$. Данные изменения указывают на восстановление железа в присутствии углерода вследствие импульснопучкового воздействия.

Повышение плотности энергии импульсного ионного пучка до $1-1.5 \mathrm{~J} / \mathrm{cm}^{2}$ способствует интенсификации процесса восстановления железа до $\mathrm{Fe}^{0}$, о чем свидетельствует полное отсутствие сигнала от окисленного железа (рис. 5, $b$ ). Помимо этого отмечается снижение интенсивности линий $\mathrm{Fe} 2 p$ и Fe $3 p$ в образцах N-MУНТ по мере роста плотности энергии импульсного ионного пучка (рис. 4,a). Минимальная интенсивность сигнала линии $\mathrm{Fe} 2 p$ наблюдается для углеродных нанотрубок, облученных при плотности энергии пучка $1.5 \mathrm{~J} / \mathrm{cm}^{2}$ (рис. 4, a, кривая 4). Количество железа для данного режима облучения составляет 0.1 at.\%. При этом для данного образца сигнал от Fe $3 p$ полностью отсутствует (рис. 4, а, кривая 4).

\section{4. Обсуждение результатов}

На основе полученных экспериментальных данных ПЭМ для N-MУНТ, облученных при плотности энергии 
$0.5 \mathrm{~J} / \mathrm{cm}^{2}$, было установлено, что ионное воздействие приводит к открытию концов нанотрубок и удалению инкапсулированных частиц катализатора (рис. 2). Наиболее вероятным механизмом этого является термическое расширение кластеров железа в вершинах нанотрубок, их плавление и испарение вследствие нагрева, инициированного импульсным ионным пучком. Это приводит к осаждению частиц железа на боковых поверхностях N-МУНТ. Оценочные значения температуры нагрева приповерхностной области слоя N-МУНТ при облучении импульсным ионным пучком с плотностью энергии от 0.5 до $1.5 \mathrm{~J} / \mathrm{cm}^{2}$, полученные нами ранее в $[17,25]$, показали, что в результате данного воздействия происходит нагрев поверхностного слоя толщиной $\sim 1 \mu \mathrm{m}$ от температур $\sim 800$ до $\sim 1800^{\circ} \mathrm{C}$ соответственно. Таким образом, облучение импульсным ионным пучком с минимальным значением плотности энергии $\left(0.5 \mathrm{~J} / \mathrm{cm}^{2}\right)$, применяемое в настоящей работе, может приводить к нагреву приповерхностной области слоя N-MУНТ до 800-900 ${ }^{\circ}$. Данных температур, как показано в работе [14], достаточно для частичного удаления катализатора из вершин нанотрубок. Анализ методом ПЭМ показал, что частицы железа на боковых поверхностях $\mathrm{N}-\mathrm{MУНТ} \mathrm{инкапсулированы} \mathrm{в} \mathrm{графитовую} \mathrm{оболочку,} \mathrm{со-}$ стоящую из нескольких графеновых слоев (рис. 2,c и $d$ ). Формирование графитовой оболочки, возможно, связано с частичной абляцией слоев нанотрубок и диффузией углерода через поверхность частиц железа [26]. Исследование методом РФЭС показало снижение доли окисленного железа при облучении импульсным ионным пучком с плотностью энергии $0.5 \mathrm{~J} / \mathrm{cm}^{2}$ (рис. 4). Согласно [27], карботермическое восстановление частиц $\mathrm{Fe}_{2} \mathrm{O}_{3}$ до Fе на поверхности МУНТ при стационарном отжиге в атмосфере гелия происходит при температуре $\sim 800^{\circ} \mathrm{C}$. Следовательно, частичное восстановление железа при облучении импульсным ионным пучком с плотностью энергии $0.5 \mathrm{~J} / \mathrm{cm}^{2}$, вероятно, обусловлено карботермическим восстановлением оксида железа, изначально присутствующего на боковых поверхностях N-MУНТ. Повышение плотности энергии от 0.5 до $1.5 \mathrm{~J} / \mathrm{cm}^{2}$ приводит к интенсификации процесса карботермического восстановления железа вплоть до его полного восстановления, а также к существенному снижению количества железа в объеме слоя, что, вероятно, связано с интенсивным испарением железа (табл. 1, 2, рис. 4). Наибольшие изменения наблюдаются для углеродных нанотрубок, облученных при плотности энергии пучка $1.5 \mathrm{~J} / \mathrm{cm}^{2}$, что объясняется нагревом поверхности слоя N-МУНТ до температур $\sim 1800^{\circ} \mathrm{C}$.

\section{5. Заключение}

В результате проведенных исследований с использованием методов ПЭМ, РФЭС и ЭДА показано, что использование импульсного ионного пучка позволяет в зависимости от режимов облучения влиять на химическое состояние железа, его распределение и концентрацию в N-МУНТ. Было показано, что облучение N-МУНТ с плотностью энергии импульсного пучка $0.5 \mathrm{~J} / \mathrm{cm}^{2}$ способствует формированию на их боковых поверхностях структур размером 2-10 nm, состоящих из металлического железа, инкапсулированного в углеродную оболочку. Наличие таких частиц, распределенных по поверхности углеродных нанотрубок, может иметь практическое применение в гетерогенном катализе. Установлено, что повышение плотности энергии до $1-1.5 \mathrm{~J} / \mathrm{cm}^{2}$ инициирует снижение количества железа в слое N-МУНТ. При этом удаление частиц катализатора (железа) из вершин углеродных нанотрубок приводит к открытию их концов за счет увеличения объема частиц катализатора, обусловленного нагревом.

Авторы выражают благодарность Ю.А. Стенькину за подготовку образцов для исследований, а также руководству ЦКП ОНЦ СО РАН за предоставление оборудования для исследования образцов методом ЭДА.

\section{Список литературы}

[1] П. Харрис. Углеродные нанотрубки. Синтез, свойства и применение. ООО ОФСЕТ-ТМ, Новосибирск (2016). $220 \mathrm{c}$.

[2] S. van Dommele, A. Romero-Izquirdo, R. Brydson, K.P. de Jong, J.H. Bitter. Carbon 46, 138 (2008).

[3] J. Gao, J. Zhong, L. Bai, J. Liu, G. Zhao, X. Sun. Sci. Rep. 4, 3606 (2014).

[4] X. Chen, J. Xiao, J. Wang, D. Deng, Y. Hu, J. Zhou, L. Yu, T. Heine, X. Pana, X. Bao. Chem. Sci. 6, 3262 (2015).

[5] T. Fu, M. Wang, W. Cai, Y. Cui, F. Gao, L. Peng, W. Chen, W. Ding. ACS Catal. 4, 2536 (2014).

[6] Yu.V. Fedoseeva, L.G. Bulusheva, A.V. Okotrub, D.V. Vyalikh, J. Huo, H. Song, J. Zhou, X. Chen. Mater. Chem. Phys. 135, 235 (2012).

[7] В.А. Цурин, А.Е. Ермаков, М.А. Уймин, А.А. Мысик, Н.Н. Щеголева, В.С. Гавико, В.В. Майков. ФТТ 56, 288 (2014).

[8] A. Meyer-Plath, G. Orts-Gil, S. Petrov, F. Oleszak, H.-E. Maneck, I. Dorfel, O. Haase, S. Richter, R. Mach. Carbon 50, 3934 (2012).

[9] V. Gomez, S. Irusta, O.B. Lawal, W.W. Adams, R.H. Hauge, C.W. Dunnill, A.R. Barron. RSC Adv. 6, 1 (2016).

[10] E.R. Edwards, E.F. Antunes, E.C. Botelho, M.R. Baldan, E.J. Corat. Appl. Surf. Sci. 258, 641 (2011).

[11] R. Andrews, D. Jacques, D. Qian, E.C. Dickey. Carbon 39, 1681 (2001).

[12] E.F. Antunes, V.G. de Resende, U.A. Mengui, J.B.M. Cunha, E.J. Corat, M. Massi. Appl. Surf. Sci. 257, 8038 (2011).

[13] W. Huang, Y. Wang, G. Luo, F. Wei. Carbon 41, 2585 (2003).

[14] H.C. Choi, S.Y. Bae, W.-S. Jang, J. Park, H.J. Song, H.-J. Shin, H. Jung, J.-P. Ahn. J. Phys. Chem. B 109, 1683 (2005).

[15] K. Fujisawa, T. Tojo, H. Muramatsu, A.L. Elıas, S.M. VegaDiaz, F. Tristan-Lopez, J.H. Kim, T. Hayashi, Y.A. Kim, M. Endoab, M. Terrones. Nanoscale 3, 4359 (2011).

[16] В.В. Болотов, П.М. Корусенко, С.Н. Несов, С.Н. Поворознюк. ФТТ 56, 802 (2014).

[17] P.M. Korusenko, V.V. Bolotov, S.N. Nesov, S.N. Povoroznyuk, I.P. Khailov. Nucl. Instrum. Meth. B 358, 131 (2015). 
[18] A.I. Pushkarev, Yu.I. Isakova, I.P. Khailov. Eur. Phys. J. D 69, 1 (2015).

[19] S. Tanuma, C.J. Powell, D.R. Penn. Surf. Interface Anal. 36, 1 (2004).

[20] I.S. Lyubutin, O.A. Anosova, K.V. Frolov, S.N. Sulyanov, A.V. Okotrub, A.G. Kudashov, L.G. Bulusheva. Carbon 50, 2628 (2012).

[21] V.V. Bolotov, V.E. Kan, E.V. Knyazev, P.M. Korusenko, S.N. Nesov, Y.A. Sten'kin, V.A. Sachkov, I.V. Ponomareva. New Carbon Mater. 30, 385 (2015).

[22] D.S. Jensen, S.S. Kanyal, N. Madaan, J.M. Hancock, A.E. Dadson, M.A. Vail, R. Vanfleet, V. Shutthanandan, Z. Zhu, M.H. Engelhard, M.R. Linford. Surf. Interface Anal. 45, 1273 (2013).

[23] P.M. Korusenko, S.N. Nesov, V.V. Bolotov, S.N. Povoroznyuk, A.I. Pushkarev, K.E. Ivlev, D.A. Smirnov. Nucl. Instrum. Meth. B 394, 37 (2017).

[24] X. Zhang, J. Zhou, H. Song, X. Chen, Yu.V. Fedoseeva, A.V. Okotrub, G.L. Bulusheva. ACS Appl. Mater. Interfaces 6, 17236 (2014).

[25] В.В. Болотов, П.М. Корусенко, С.Н. Несов, С.Н. Поворознюк, Ю.А. Стенькин. Омск. науч. вестн. 148, 119 (2016).

[26] V. Labunov, A. Prudnikava, S. Bushuk, S. Filatov, B. Shulitski, B.K. Tay, Y. Shaman, A. Basaev. Nanoscale Res. Lett. 8, 1 (2013).

[27] W. Chen, X. Pan, M.-G. Willinger, D.S. Su, X. Bao. J. Am. Chem. 128, 3136 (2006). 